\title{
Avaliação do sofrimento psíquico da mãe acompanhante em alojamento conjunto pediátrico
}

\author{
Evaluation of the psychological suffering of the mother \\ who rooms in with her child at a pediatric hospital
}

\author{
Jaquilene Barreto da COSTA ${ }^{1,2}$ \\ Mônica Augusta MOMBELLI ${ }^{3}$ \\ Sonia Silva MARCON ${ }^{4}$
}

\begin{abstract}
Resumo
Este estudo objetivou apreender os sentimentos vividos pela mãe que acompanha um filho internado e identificar as estratégias de enfrentamento utilizadas para lidar com essa realidade. Tratou-se de uma pesquisa qualitativa que utilizou como técnica para coleta de dados o procedimento Desenho-Estória, aplicado junto a 17 mães que acompanhavam seus filhos em alojamento conjunto pediátrico de um hospital universitário. Realizou-se, na análise dos dados, a interpretação psicológica dos desenhos e análise do conteúdo das falas apresentadas na estória contada pela mãe a partir dos desenhos. Para tanto, utilizou-se na interpretação dos desenhos o referencial teórico proposto por van Kolck. Os dados com as falas dos sujeitos foram analisados nos moldes da análise de conteúdo proposto por Minayo. Observou-se a expressão do sofrimento psíquico a partir dos sentimentos de medo, preocupação, impotência e tristeza, geradores de ansiedade e angústia.
\end{abstract}

Unitermos: Enfrentamento. Família. Hospitalização. Sofrimento psíquico.

\begin{abstract}
This study aimed to capture the feelings experienced by the mother who accompanies her child when admitted to hospital and also to identify the coping strategies used to deal with this situation. This is a qualitative study that used the Drawing-Story procedure as the data collection technique, applied to 17 mothers who roomed in with their children in a Pediatric Ward of a University Hospital. The psychological interpretation of the drawings was used in the analysis of the data, and also the analysis of the content of the language used in the story told by the mother, based on the drawings. For this purpose, the theoretical framework proposed by van Kolck was used to interpret the drawings. The data containing the words used by the individuals were analyzed along the lines of the content analysis proposed by Minayo. An expression of mental suffering was observed out of feelings of fear, concern, helplessness, sadness, leading to anxiety and anguish.
\end{abstract}

Uniterms: Coping behavior. Family. Hospitalization. Mental suffering.

VरV V

1 Universidade Estadual de Maringá, Programa de Pós-Graduação - Mestrado em Ciências da Saúde. Maringá, PR, Brasil.

2 Hospital Universitário do Oeste do Paraná, Setor de Psicologia. Av. Tancredo Neves, 3224, Santo Onofre, 85806-470, Cascavel, PR, Brasil. Correspondência para/Correspondence to: J.B. COSTA. E-mail: <jaquihuop@yahoo.com.br>.

3 Universidade Estadual de Maringá, Programa de Pós-Graduação Mestrado em Ciências da Saúde. Maringá, PR, Brasil.

4 Universidade Estadual de Maringá. Núcleo de Estudo, Pesquisa, Assistência e Apoio à Família. Maringá, PR, Brasil. 
A assistência à criança hospitalizada em alojamento conjunto pediátrico é parte de um trabalho amplo que envolve distintos agentes, entre esses, a equipe, o paciente e a sua família, especificamente aquele familiar que o acompanha durante a internação. Os agentes envolvidos neste contexto geralmente estão expostos a diferentes sentimentos que podem acarretar sofrimento psíquico.

Para Monticelli (2004) a realidade clínica do alojamento conjunto pediátrico apresenta-se como uma dimensão social e simbólica, na qual estão presentes relações intrafamiliares, interprofissionais e entre as famílias e os profissionais, em que são estabelecidas redes de interesse diversificadas, uma vez que prevalecem diferentes poderes e saberes.

A hospitalização é uma experiência estressante, dadas as situações em que ela ocorre, e envolve profunda adaptação do paciente às várias mudanças decorrentes do processo de internação, independentemente de sua idade. A internação imediata, a separação de casa e do convívio familiar, além dos procedimentos terapêuticos que, muitas vezes, agridem o paciente física e emocionalmente, são fatores desestruturantes tanto para a criança quanto para os familiares.

A reação da criança diante da doença está diretamente relacionada a múltiplos fatores que interferem nas reações emocionais frente à internação. Os mais comuns são: a idade da criança, a natureza da doença, a duração da internação, o afastamento do lar, a limitação das atividades, as experiências anteriores com o adoecer e as vividas durante a hospitalização, além da atitude dos pais frente ao adoecimento e da qualidade de suas relações parentais (Chiattone, 1988).

A hospitalização de uma criança traz a família para o interior do hospital, outro elemento além do paciente e da equipe de saúde, que passa a fazer parte desse grupo de relações.

As interações doença/família vêm sendo cada vez mais estudadas, e mudanças são observadas nas práticas de saúde, permitindo uma percepção integral, com novos enfoques terapêuticos. Estudos apontam que a hospitalização de um filho pode desencadear alterações emocionais e sofrimento psíquico nos membros da família, principalmente naquele que acompanha a criança (Heneghan, Mercer \& De Leone, 2008; Kohlsdorf
\& Costa Junior, 2008; Milanesi, Collet, Oliveira \& Vieira, 2006; Oliveira \& Angelo, 2000; Méllo \& Rodrigues, 2008).

O mundo do hospital, com seus sistemas, dinâmica e rotina, é muito diferente daquele que a família conhece. A convivência neste ambiente permeado por pessoas e organização peculiar provoca alterações emocionais tanto na criança quanto na família (Costa, Collet \& Gonçalves, 2007).

Além de ter que conviver com a doença, a criança e a família precisam se adaptar a esse novo ambiente e às novas situações presentes. Ziegel e Cranley (1995) afirmam que toda família passa por alguns estágios quando enfrenta uma situação de crise: vivencia certa desorganização familiar até a sua reorganização no decorrer desse processo.

É por essa razão que o surgimento da doença, especialmente quando exige hospitalização, constitui quase sempre fator desestruturante para a família. 0 adoecimento pode aparecer então como uma ameaça, não só à criança, mas também à família (Diaz-Caneja, Gledhill, Weaver, Nadel \& Garralda, 2005), ameaça esta que assume proporções equivalentes à gravidade da doença. A família, então, defronta-se com duas tarefas: cuidar da criança doente e lidar com as emoções, a maioria das vezes inconscientes, que passam a transformar as relações entre seus membros.

Assim, a doença interrompe a forma habitual de vida da criança e de seus familiares, configurando um estado de crise, agravado por algumas características específicas determinadas pela hospitalização, com suas intricadas relações e com as reações dos agentes envolvidos; é necessária, portanto, uma intervenção a partir do reconhecimento precoce e do manejo eficiente desse sofrimento.

A partir dessa relação doença/família/ambiente, a criança e seu acompanhante precisam lançar mão de alguns recursos de enfrentamento para modificar a sua relação com o ambiente. Muitos estudos investigam recursos de enfrentamento e os diversos fatores que interferem no modo como os indivíduos lidam com os diferentes eventos ambientais a que são expostos ao longo do ciclo de vida (Coyne \& Racioppo, 2000; Kohlsdorf \& Costa Junior, 2008; Norberg, Lindblad \& Boman, 2005).

No estudo aqui descrito, especificamente, o enfrentamento corresponde aos esforços cognitivos e 
comportamentais utilizados pela mãe para lidar com as demandas durante a internação de seu filho, com o objetivo de reduzir, eliminar ou manejar as situações percebidas pela mãe como causadoras de sofrimento psíquico.

Os objetivos propostos e os dados apresentados neste estudo podem contribuir para o avanço nas discussões acerca da atenção e do cuidado com a família, além de possibilitar a utilização de novos instrumentos de análises dentro desse contexto. Desse modo, a realização de pesquisas com vistas a produzir dispositivos de intervenção no cotidiano do ambiente hospitalar amplia as ações, em uma perspectiva de atuação interdisciplinar, visando a uma assistência integral e de qualidade.

\section{Método}

Optou-se pela realização de uma pesquisa de campo de natureza qualitativa, considerando que esse tipo de estudo oferece uma perspectiva ampla para a exploração dos conhecimentos que se deseja adquirir. Segundo Minayo (2007), esse tipo de pesquisa preocupa-se com um nível de realidade que não pode ser quantificado, ou seja, visa à compreensão e explicação da dinâmica social, trabalhando com um universo de crenças, valores, atitudes, motivos e aspirações. Assim, esse método interpreta o conteúdo das falas, ultrapassando a mensagem e atingindo os significados latentes.

\section{Local do Estudo}

O estudo foi realizado em um hospital universitário localizado no município de Cascavel, com capacidade para 173 leitos, referência de alta complexidade em atendimento de urgência e emergência para as regiões Oeste e Sudoeste do Paraná, prestando atendimento em diversas especialidades.

A Unidade de Alojamento Conjunto Pediátrico, local da coleta de dados, atende crianças com idade entre 29 dias e 14 anos com diversas patologias clínicas e cirúrgicas. Sua capacidade é de 28 leitos, entre berços para crianças de zero a cinco anos e camas-leito para crianças maiores e adolescentes, e conta com um total de dez enfermarias, todas com banheiro privativo para as crianças e acomodações para as mães/acompanhantes (poltronas reclináveis). Além das enfermarias, a unidade conta com salas de procedimentos, de admissão da criança, de recreação e uma sala de informática denominada Escola de Informática e Cidadania (EIC- Hospitais), um refeitório e um playground com solário. Para a família, é oferecida uma sala com banheiros e armários para guardar seus pertences.

As crianças admitidas na Unidade de Alojamento Conjunto Pediátrico são provenientes do Serviço de Pronto-Socorro (PS) do próprio hospital, bem como de outros serviços de saúde do município e região. Essa unidade assegura o direito da mãe ou acompanhante de estar com a criança no período de internação, bem como participar dos procedimentos hospitalares, ter informações a respeito do quadro clínico e fazer a troca de acompanhante.

\section{Procedimentos}

Os dados foram coletados nos meses de junho e julho de 2007, utilizando como estratégia uma adaptação da técnica do Desenho-Estória de Trinca (2003). Essa técnica consiste em pedir ao sujeito que realize uma série de desenhos livres (cinco unidades de produção), cromáticos ou acromáticos, e em seguida é solicitado que se conte uma estória, associada livremente, a partir daquele estímulo. Após o término da estória o examinador segue com a fase de inquérito, na qual faz alguns questionamentos para esclarecimento do material produzido e para estimular novas associações acerca desse material e, por fim, pede-se o título da estória.

O desenho como um instrumento projetivo funciona como técnica de apercepção temática, uma vez que o sujeito faz o desenho e conta uma estória baseada em sua produção gráfica. O desenho e a estória funcionam como mecanismos facilitares para acesso aos conteúdos inconscientes. Entretanto, a partir da interpretação dos dados coletados pode-se constatar o significado latente apresentado no conteúdo de caráter projetivo (Tsu \& Borges, 1991).

A adaptação da técnica foi necessária porque, em estudo anterior, foi constatada dificuldade em concluir a participação no estudo em função da alta hospitalar da criança (Costa et al., 2007). Assim, foram 
propostas duas unidades de desenho: um desenho livre e um temático, realizados em uma única sessão, com duração média de uma hora e trinta minutos. O desenho livre foi solicitado da seguinte forma: "você tem esta folha em branco e pode fazer o desenho que quiser e da forma como souber". Após a realização do desenho livre foi solicitado outro desenho com o tema: "como você se sente em acompanhar seu filho(a) internado(a)?". Após o término de cada desenho foi solicitado às mães que contassem uma estória usando o desenho apresentado e atribuíssem a ela um título.

Segundo Stern, citado porTrinca (2003):"quando o sujeito não pode se expressar verbalmente seja por pouca idade, no caso de crianças, porque sofre de algumas inibições ou dificuldades, seja devido a qualquer outra razão, a expressão gráfica satisfaz mais do que a verbal". Por outro lado, o desenho é porta de acesso ao inconsciente, ou, em outras palavras, ao mundo interno do sujeito, possibilitando a expressão de seus sentimentos e a comunicação de seus conflitos intrapsíquicos.

As mães participantes da pesquisa foram selecionadas aleatoriamente durante o período do estudo, considerando-se apenas a disponibilidade e anuência das mesmas em participar, independentemente da doença e tempo de internação da criança. O número de participantes não foi estabelecido previamente; assim, quando os dados tornaram-se repetitivos, considerou-se atingida a saturação teórica.

A técnica do Desenho-Estória foi aplicada individualmente e em local reservado dentro da própria unidade. A estória contada a partir do desenho foi gravada pelo examinador e, posteriormente, transcrita na íntegra. Todo o material coletado foi submetido a tratamento de análise por meio da interpretação psicológica dos desenhos e análise do conteúdo da estória contada pela mãe a partir do desenho, buscando compreender os significados dos sentimentos vividos pela mesma durante a hospitalização e quais os recursos de enfrentamento utilizados para lidar com essa situação.

Os dados com as falas dos sujeitos foram analisados nos moldes da análise de conteúdo proposta por Minayo (2007). Para tanto, realizou-se a leitura repetida das estórias relatadas, a classificação e a reagrupação dos dados mais relevantes. Esse procedimento, somado são dos conteúdos relacionados ao sofrimento psíquico expressos nas estórias relatadas.

Para análise e interpretação dos desenhos utilizou-se como referencial teórico o proposto por van Kolck (1984), considerando-se os aspectos adaptativos, expressivos e projetivos dos desenhos. Quanto aos aspectos adaptativos, verificou-se se a produção estava de acordo com o solicitado. Para avaliação dos aspectos expressivos, analisou-se o significado geral dos desenhos. Para a análise dos aspectos projetivos, buscou-se identificar os fenômenos inconscientes, que incluem a dinâmica encoberta de conflitos e a apreensão simbólica do sofrimento psíquico. A análise foi realizada comparando o desenho livre e o temático, enfatizando as diferenças apresentadas nestas produções.

A realização do estudo obedeceu aos preceitos éticos disciplinados pela Resolução 196/96 do Conselho Nacional de Saúde e o projeto de pesquisa foi aprovado pelo Comitê de Ética em Pesquisa com Seres Humanos da Universidade Estadual de Maringá (Parecer n॰208/2007). Tendo em vista a preservação da identidade das participantes, estas foram identificadas com a inicial de seu primeiro nome, e quando as iniciais foram coincidentes acrescentou-se a inicial do sobrenome. Todas as participantes do estudo assinaram Termo de Consentimento Livre e Esclarecido em duas vias.

\section{Resultados e Discussão}

\section{Análise do conteúdo das estórias contadas}

Participaram da pesquisa 17 mães que acompanhavam seus filhos internados na referida instituição durante o período de coleta de dados. As mães em estudo tinham idade entre 14 e 45 anos; destas, 70,6\% estavam na faixa etária entre 20 e 40 anos, 70,6\% tinha mais de um filho, 64,7\% eram do lar, 70,6\% eram casadas e a maioria $(52,9 \%)$ tinha cinco anos de escolaridade. Quanto às crianças internadas, 76,5\% eram maiores de um ano de idade, $82,4 \%$ tinham mais de 72 horas de internação, 58,8\% já haviam sido internadas anteriormente e $64,7 \%$ das mães referiram não fazer troca de acompanhante durante o internamento, permanecendo em tempo integral junto ao filho.

Os resultados retratam a vivência da mãe ao acompanhar um filho internado: ela fala de seus 
sentimentos e da dificuldade de permanecer no hospital. Observou-se, por meio do conteúdo das falas, que no ambiente hospitalar há muitos fatores estressantes que podem desencadear sofrimento, como exemplifica o trecho de uma das estórias: "Eu me sinto presa aqui, por isso desenhei uma cerca. Considero o hospital uma prisão para o bem porqueénecessário para meu filho ficar beme pronto para ir para a casa. A estrada (no desenho) representa a liberdade éo caminho que melevará de volta para $\operatorname{casa}\left(V_{\text {. }) \text {. }}\right.$

A tensão é decorrente tanto dos sentimentos vividos em relação à doença do filho quanto dos fatores provenientes do ambiente hospitalar, uma vez que inicialmente a hospitalização é percebida como uma ameaça.

Esse aspecto foi relatado em outros estudos, que destacam que a situação de internação exige da mãe o desprendimento do seu cotidiano, do qual tinha domínio, para vivenciar a realidade institucional delimitada pelas suas normas e rotinas (Dittz, Mota \& Sena, 2008; Milanesi et al., 2006).

Analisando a relação entre o sofrimento e a forma como as mães lidam com esta situação, observou-se que o sofrimento assume diferentes contornos, tornando-se mais ou menos intenso dependendo do significado atribuído à doença, à gravidade da doença, à experiência de internação e o que esta provoca em seu dia a dia.

Nesse sentido, as mães que acompanham o filho internado por um longo período projetaram nos desenhos vários aspectos que compõem a situação de hospitalização e que são geradores de sofrimento. As estórias relatadas são permeadas de expressões de sofrimento diante desta vivência: "Me sinto culpada, triste, conforme ele melhora isto alivia. Falei pra ele que se eu pudesse trocar de lugar com ele eu trocaria e passaria por tudo isto no lugar dele. Quero muito ir embora, para casa, mas só vamos quando estiver certa de que está tudo bem, não quero perder meu filho (I.). Me sinto muito triste, em desespero, sem saber o que fazer. Me desenhei chorando, desesperada, ao lado dele, sem poderfazer nada. Aquivocê fica encucada porque tem que conviver com as outras crianças doentes, com problemas sérios (S.). No hospital há momentos em que nos sentimos presas, fico muito nervosa eangustiada. (...).(V.).
Identificou-se no conteúdo das estórias contadas pelas mães a expressão do sofrimento vivido em decorrência da hospitalização de um filho. Sentimentos como a tristeza, o desespero, a angústia e o nervosismo são expressos de forma intensa pela mãe, caracterizando-se como sofrimento psíquico. A vivência desse sofrimento, por sua vez, pode desencadear o surgimento de transtornos emocionais, além de tornar o acompanhamento do filho uma tarefa penosa, principalmente quando não há, por parte da mãe, a utilização de recursos internos mais elaborados para lidar com esta situação geradora de angústia e ansiedade e quando não é possível a expressão desse sofrimento.

Em estudo realizado por Diaz-Caneja et al. (2005), que comparou a experiência de pais de crianças internadas em Unidade de Terapia Intensiva Pediátrica (UTI-P) e aqueles com crianças internadas em enfermaria pediátrica geral, observou-se que nos dois grupos a experiência descrita foi similar à reação de perda, com sentimentos de culpa, choque, descrença na situação, além do uso de estratégias de esquiva, como evitar o contato com outras crianças doentes e com a equipe devido ao medo de ter informações ruins sobre o quadro clínico da criança. Este último comportamento ocorreu, principalmente, no grupo de pais de crianças internadas na UTI-P que apresentavam maior gravidade.

Para Savoia (2000), a compreensão dos processos de enfrentamento e de seus significados é fundamental para o bem-estar psicossocial, uma vez que visa ao aumento do controle pessoal e depende do repertório individual (por exemplo, habilidades sociais e de solução de problemas, valores e crenças culturais) e de experiências tipicamente reforçadoras. Nesse sentido, os diversos comportamentos e condutas adotados pelas mães são resultantes de seu sofrimento e da maneira como o enfrentam.

Percebeu-se que o estado afetivo da mãe, expresso pelos sentimentos de temor, ansiedade, desespero, impotência, saudade, solidão, preocupação, insegurança, medo, tristeza, entre outros, está diretamente relacionado à situação de hospitalização, e que o afloramento desses sentimentos constitui resposta emocional às solicitações de adaptação.

Esses dados podem ser correlacionados com o estudo de Ribeiro (2004), no qual o medo foi identificado como um dos sentimentos verbalizado com maior 
frequência pela família da criança hospitalizada, caracterizando-se também como pânico, preocupação, angústia, desespero, susto e receio. Segundo esta autora, os sentimentos vivenciados pela família com frequência colaboram para determinar seu comportamento, associando-se a outros fatores na trajetória da família e sua história de doença. Logo, a maioria das mães relatou a experiência de internação como algo ruim, que mobiliza sentimentos difíceis e que, portanto, intensificam o desejo de ir para casa. "Quero ir para casa, mas não posso deixar ele, quando estou aquiele se sente melhor" (E.)."O que eu mais quero é voltar para casa" (A.)."Eu e meu filho queremos ir para casa, mas só vou quando estiver certa de queestá tudo bem"(I.).

Observou-se que as mães que tinham filhos com histórico de internações anteriores devido a uma doença de base e que permaneciam com seu filho por muito tempo internado vivenciavam os sentimentos descritos de forma exacerbada. Elas precisam aprender a lidar com seus sentimentos e suportá-los para conseguir permanecer junto ao filho e, muitas delas, além da situação de hospitalização, devem conviver concomitantemente com os medos de seu cotidiano, que envolvem a preocupação com os outros filhos, esposo, trabalho, além daqueles presentes no ambiente hospitalar.

\section{Estratégias de enfrentamento}

Quando questionadas sobre como fazem para lidar com os sentimentos presentes na situação de internamento, várias mães referiram o uso de recursos individuais para suportar esta situação. "Quando estou muito angustiada procuro conversar com as outras mães dos pacientes" (S.). "Quando estou muito nervosa e angustiada fico no quarto sozinha e em silêncio, ou vou para a sala de recreação realizar alguma atividade" (N.).

Observa-se que as mães utilizam recursos internos e externos para suportar essa situação, entre eles: conversar com os outros, brincar com o filho, chorar, procurar se ocupar, rezar e ficar sozinha em silêncio. Desta forma, fazem uso de estratégias individuais e muito particulares para enfrentar os sentimentos vividos no decorrer da hospitalização de seu filho.

Dados da literatura também indicam que a fé e a religiosidade são estratégias bastante utilizadas.
Segundo Lima (2000), alguns estudos sugerem que a prática religiosa facilita o desenvolvimento de estratégias de enfrentamento. No estudo realizado por Elkin et al. (2007), que focalizou a relação entre religiosidade e enfrentamento, os resultados mostraram baixos escores em sintomas depressivos relacionados a altas pontuações em práticas religiosas, sinalizando uma importante relação entre religiosidade e enfrentamento adaptativo.

No estudo de Sterken (1996), realizado com pais de crianças em tratamento de câncer, as principais estratégias de enfrentamento foram descritas como evasivas e com foco em conteúdos emocionais. Como exemplos de respostas de enfrentamento similares ao estudo aqui descrito, os participantes relataram choro, práticas religiosas, pensamentos positivos e comparações com o estado físico de outros pacientes.

Nesta direção, Santos (2001) menciona a importância de atividades de lazer como uma estratégia de convivência com a doença, e Ribeiro (2004) fala do choro como uma manifestação de medo, tristeza ou raiva. A seguir, apresentam-se algumas falas que ilustram esses dados: "Quando estou muito nervosa, rezo bastante, oro a Deus, choro muito" (E.). "Rezo muito para o médico dos médicos, que é Deus, sou evangélica e acredito que isto vai passar" (I.). "Quando não estou tranquila, vou ao parquinho evenho aqui na sala de recreação" (A.). "Eu costumo chorar quando estou ansiosa, daí alivia um pouco, ou ando pelo corredor" (A.R.).

As estratégias utilizadas pelas mães têm a finalidade de transformar o sofrimento em uma vivência suportável, tanto para elas quanto para as crianças. Por meio desses recursos e com a possibilidade de sua expressão dentro da unidade, a mãe assume um papel mais ativo, na medida em que utiliza recursos próprios para minimizar e modificar a realidade vivida.

O estudo de Rodrigues, Rosa, Moura e Baptista (2000) revelou que as estratégias de enfrentamento mais eficientes utilizadas pelos pais estiveram associadas a uma melhor adaptação comportamental ao contexto de tratamento médico das crianças.

James et al. (2002) ressaltam que quando os pais percebem que não dispõem de recursos psicológicos suficientes para atender aos cuidados da criança em tratamento, bem como às demandas dos demais fami- 
liares, tal condição pode constituir uma barreira ao desenvolvimento de estratégias eficientes de enfrentamento, requerendo da equipe de saúde a implementação imediata de intervenções psicossociais.

\section{Análise psicológica dos desenhos}

Na análise comparativa entre o desenho livre e o temático identificaram-se algumas diferenças significativas. A maioria dos desenhos livres foi realizada com riqueza de detalhes, uso de cores mais vibrantes, apresentando uma qualidade gráfica melhor. Já no desenho temático foi observado um decréscimo na qualidade gráfica e nos recursos utilizados para enriquecê-lo. As participantes fizeram pouco uso da cor e de detalhes, o que pode estar associado às vivências difíceis, tais como a internação, o tratamento e o isolamento familiar. A cor é a expressão da afetividade e a não utilização sugere que a vivência de internação pode produzir um embotamento afetivo, observando-se aumento dos impulsos inibidores quando a mãe é confrontada e colocada diante de tal situação, sugerindo repressão do afeto. A mãe demonstra dificuldade de entrar em contato com os sentimentos mobilizados pela situação de internamento.

O tamanho do desenho temático, em sua maioria, foi menor quando comparado ao desenho livre, o que exprime a relação da mãe com o ambiente, sugerindo certa dificuldade em lidar com a situação de hospitalização do filho. O desenho livre foi apresentado em tamanho grande, expressando uma tentativa de adequação ao ambiente. Quanto ao conteúdo dos desenhos livres, os temas apresentados com mais frequência foram o desenho da árvore, da figura humana, da casa, do sol, além da presença de outros desenhos menos frequentes, como flores, frutas, nuvens, montanhas etc.

Optou-se, neste estudo, por analisar os desenhos que apareceram com maior frequência, a exemplo do desenho da casa e da figura humana. O significado atribuído ao desenho da casa foi a representação das relações familiares, expressando a percepção da situação do lar, seja ela presente ou desejada. A frequência do desenho da casa pode também representar a busca de afeto, de seus pares, o local onde se busca segurança, onde são satisfeitas as necessidades básicas, elementos necessários para a manutenção da saúde mental. Além disso, o desenho da casa pode expressar o desejo da mãe de retornar ao lar e viver a vida como ela era antes do internamento.

Já o desenho da figura humana representou, na maioria das produções, a vivência de internação da criança em companhia de sua mãe. Em alguns desenhos os sujeitos representaram a figura humana dentro do contexto hospitalar e, em outros, a figura humana estava acompanhada de outros membros da família, simbolizando situações vividas dentro do contexto familiar.

Observou-se que as mães utilizaram um tempo maior para realizar o desenho livre; em sua grande maioria foi apresentado de forma colorida, expressando o prazer em fazê-lo. Já o desenho temático foi concluído em tempo menor, e algumas mães tiveram dificuldade de iniciá-lo. O tempo menor no desenho temático foi analisado em relação à dificuldade da mãe de entrar em contato com sentimentos mobilizadores de ansiedade. Falar (desenhar) sobre a experiência de acompanhar um filho internado traz para a mãe a percepção desta vivência, gerando angústia e resistência para externalizar esses sentimentos.

O relato das histórias contadas a partir do desenho temático trouxe à tona ideias, sentimentos e preocupações em torno de questões relacionadas à distância de casa, à saudade dos demais, às interações com os profissionais do hospital, bem como sentimentos de culpa, tristeza e incapacidade frente à situação. Enquanto desenhavam, as mães apresentavam uma atitude de autoquestionamento a respeito da situação, ou seja, expressavam o desejo de obter informações precisas sobre a internação.

Os símbolos projetados pelos sujeitos da pesquisa no desenho livre (árvores, casas, pessoas, flores etc.), portanto, refletiram a dinâmica de sua personalidade. Já no desenho temático, as participantes projetaram em símbolos característicos do ambiente hospitalar sentimentos particulares referente à sua vivência de internação junto de seu filho.

\section{Considerações Finais}

Neste estudo observou-se que a hospitalização é uma experiência estressante, que envolve profunda 
adaptação do paciente e da família às várias mudanças decorrentes do processo de internação. A internação imediata, a separação de casa e do convívio familiar, além dos procedimentos terapêuticos, foram fatores desestruturantes tanto para a criança quanto para os familiares.

A técnica do Desenho-Estória mostrou-se adequada principalmente por facilitar o diálogo com os sujeitos, criando um ambiente menos ansiogênico para investigar aspectos difíceis de abordar, e por possibilitar o acesso a conteúdos inconscientes.

Os desenhos apresentados e o conteúdo das estórias relatadas pelos sujeitos do estudo retratam os sentimentos vividos durante o acompanhamento de um filho internado. A expressão de sentimentos de medo, preocupação, tristeza, solidão e desconfiança caracterizou o sofrimento psíquico vivido pelas mães no decorrer da hospitalização.

Observou-se que as mães utilizam estratégias individuais e próprias para lidar com os sentimentos vividos na hospitalização de um filho. Trata-se de uma relação dinâmica entre o sofrimento e os recursos usados para enfrentá-lo, com o objetivo de preservar a saúde mental. Assim, as estratégias defensivas caracterizaram-se por ações adaptativas acionadas em situações penosas, com vistas a evitar o sofrimento mental.

Portanto, diante do sofrimento ou de uma situação estressante, a mãe emprega recursos de enfrentamento segundo sua estrutura de personalidade, desejos, vivências, necessidades; ou seja, tomada por um determinado sofrimento, uma mãe pode reagir de forma agressiva para descarregar a tensão, já outra pode usar de outro mecanismo para lidar com a mesma vivência.

O sofrimento vivido pelas mães assumiu diferentes contornos, tornando-se mais ou menos intenso dependendo do significado que as mesmas atribuem à doença, às situações envolvidas nesse processo e ao que a doença provoca em seu dia a dia.

Percebeu-se que as mães que acompanham seus filhos internados reagem de forma particular às diversas situações que permeiam o ambiente hospitalar. Os diversos comportamentos e condutas adotados pelas mães são atitudes que resultam de seu sofrimento e da maneira como o enfrentam.
Estabelecer uma relação de confiança, respeito e suporte entre os profissionais de saúde e a família significa a possibilidade de transformar o ambiente hospitalar em um local de menos sofrimento tanto para a criança quanto para a família. Uma atitude acolhedora da equipe oferece à criança e à família condições necessárias para suportar os sentimentos vividos no enfrentamento da doença e na situação de internamento.

Por fim, cabe salientar que este estudo foi realizado em um único hospital-escola público, centro de referência de alta complexidade. Os pacientes admitidos apresentam patologias clínicas mais graves, ou são admitidos devido a uma situação de emergência (trauma, acidentes domésticos). Desta forma, a experiência das mães e acompanhantes pode estar relacionada a esta situação em particular.

Outro aspecto importante é a baixa condição socioeconômica e cultural das famílias atendidas nesta instituição. As experiências vividas por esse grupo específico podem não refletir a vivência de outros grupos com características socioeconômicas diferentes, sendo esta uma limitação para a generalização dos resultados.

\section{Referências}

Chiattone, H. B. C. (1988). A criança e a hospitalização. In V. A. Angerami-Camon (Org.), Psicologia hospitalar: a atuação do psicólogo no contexto hospitalar (pp.40-130). São Paulo: Traço Editora.

Coyne, J. C., \& Racioppo, M. W. (2000). Never the twain shall meet? Closing the gap between coping research and clinical intervention research. American Psychologist, 55 (6), 655-664

Costa, J. B., Collet, N., \& Gonçalves, B. R. (2007). Sofrimento psíquico da criança hospitalizada. Revista Paulista de Enfermagem, 26 (2), 79-86.

Diaz-Caneja, A., Gledhill, J., Weaver, T., Nadel, S., \& Garralda, E. (2005). A child's admission to hospital: a qualitative study examining the experiences of parents. Intensive Care Medice, 31 (2), 1248-1254.

Dittz, E. S., Mota, J. A. C., \& Sena, R. R. (2008). O cotidiano no alojamento materno, das mães de crianças internadas em uma Unidade de Terapia Intensiva Neonatal. Revista Brasileira de Saúde Materno Infantil, 8 (1), 75-81.

Elkin, T. D., Jensen, S. A., McNeil, L., Gilbert, M. E., Pullen, J., \& McComb, L. (2007). Religiosity and coping in mothers of children diagnosed with cancer: an exploratory analysis. Journal of Pediatric Oncology Nursing, 24 (5), 274-278. 
Heneghan, A. M., Mercer, M. B., \& De Leone, N. L. (2008). Will mothers discuss parenting stress and depressive symptoms with their child's pediatrician. Pediatrics, 113 (3), 460-467.

James, K., Keegan-Wells, D., Hinds, P. S., Kelly, K. P., Bond, D., Hall, B., Mahan R., Moore, I.M., Rool, L., \& Speckhart, B. (2002). The care of my child with cancer: parents perceptions of caregiving demands. Journal of Pediatric Oncology Nursing, 19 (6), 218-228.

Kohlsdorf, M., \& Costa Junior, A. L. (2008). Estratégias de enfrentamento de pais de crianças em tratamento de câncer. Estudos de Psicologia (Campinas), 25 (3), 417-429.

Lima, M. V. O. (2000). Terapia cognitivo comportamental e religiosidade. In R. G. Wielennska. Sobre comportamento e cognição:questionando e ampliando a teoria e intervenção clinica em outros contextos (pp.222-227). Santo André: Esetec.

Méllo, D. C., \& Rodrigues, B. M. R. D. (2008). O acompanhante de criança submetida à cirúrgia cardíaca: contribuição para a enfermagem. Escola Anna Nery Revista de Enfermagem, 12 (2), 237- 42.

Milanesi, K., Collet, N., Oliveira, B. R. G., \& Vieira, C. S. (2006). O sofrimento psíquico da família de crianças hospitalizadas. Revista Brasileira de Enfermagem, 59 (6), 769-74.

Minayo, M. C. S. (2007). O desafio do conhecimento: pesquisa qualitativa em saúde (11a. ed.). São Paulo: Abrasco.

Monticelli, M. (2004). A família e a enfermagem em alojamentos conjuntos: saberes, poderes e experiências relacionais. In I. Elsen, S. S. Marcon \& M. R. S. Silva (Orgs.), O viver em família e sua interface com a saúde e a doença (pp.137-150). Maringá: Eduem.

Norberg, A. L., Lindblad, F., \& Boman, K. K. (2005). Coping strategies in parents of children with cancer. Social Science \& Medicine, 60 (5), 965-975.

Oliveira, I., \& Angelo, M. (2000). Vivenciando com o filho uma passagem difícil e reveladora: a experiência da mãe acompanhante. Revista da Escola de Enfermagem USP, 34 (2), 202-8.
Ribeiro, N. R. R. (2004). A família enfrentando a doença grave da criança. In I. Elsen, S. S. Marcon \& M. R. S. Silva (Orgs.), O viver em família e sua interface com a saúde e a doença (pp.183-198). Maringá: Eduem.

Rodrigues, M. A., Rosa, J., Moura, M. J., \& Baptista, A. (2000). Ajustamento emocional, estratégias de coping e percepção da doença em pais de crianças com doença do foro oncológico. Psicologia, Saúde \& Doenças, 1 (1), 61-68.

Santos, A. R. R. (2001). Avaliação da dor em pacientes com câncer: contribuições psicoterápicas. Dissertação de mestrado não-publicada, Pontifícia Universidade Católica de Campinas.

Savoia, M. G. (2000). Instrumentos para a avaliação de eventos vitais e de estratégias de enfrentamento (coping) em situações de estresse. In L. H. S. Gorenstein \& A. W. Z. Andradre (Eds.), Escalas de avaliação clínica em psiquiatria e psicofarmacologia. São Paulo: Lemos-Editorial.

Sterken, D. J. (1996). Uncertainty and coping in fathers of children with cancer. Journal of Pediatric Oncology Nursing, 13 (2), 81-88.

Trinca, W. (2003). Investigação clínica da personalidade: o desenho livre como estímulo de a percepção temática (3a. ed.). São Paulo: Epu.

Tsu T., \& Borges, T.W. (1991). Vício e loucura: estudo de representações sociais de escolares sobre doença mental, através do uso do procedimento de desenhos-estórias com tema. Boletim de Psicologia, 10 (4), 47-55.

van Kolck, O. L. (1984). Técnicas projetivas gráficas no diagnóstico psicológico. São Paulo: EPU.

Ziegel, E., \& Cranley, M. S. (1995). Enfermagem obstétrica. Rio de Janeiro: Guanabara Koogan.

Recebido em: 13/2/2008

Versão final reapresentada em: 19/1/2009

Aprovado em: 3/2/2009 